\title{
Classification of beef carcasses from Portugal using animal characteristics and $\mathrm{pH} /$ temperature decline descriptors
}

\author{
V.A.P. Cadavez ${ }^{\mathrm{a}, *}$, C. Xavier ${ }^{\mathrm{b}, \mathrm{c}}$, U. Gonzales-Barron ${ }^{\mathrm{a}}$ \\ ${ }^{\text {a }}$ CIMO Mountain Research Center, School of Agriculture, Polytechnic Institute of Braganza, Portugal \\ ${ }^{\mathrm{b}}$ REQUIMTE, LAQV, ICBAS, Instituto de Ciências Biomédicas de Abel Salazar, Universidade do Porto, Rua de Jorge Viterbo Ferreira n. ${ }^{228,} 4050-313$ Porto, Portugal \\ ${ }^{\mathrm{c}}$ REQUIMTE, LAQV, DGAOT, Faculdade de Ciências, Universidade do Porto, Rua do Campo Alegre s/n, 4169-007 Porto, Portugal
}

\section{A R T I C L E I N F O}

\section{Keywords:}

Beef

Carcass

Cold-shortening

Tenderness

\begin{abstract}
A B S T R A C T
Previous research showed that meat of optimal tenderness is produced when rigor mortis temperature falls between $12-35^{\circ} \mathrm{C}$. This study aimed to classify beef carcasses quality according to the ideal window rule using $\mathrm{pH} /$ temperature decay descriptors and animal characteristics. Seventy-four Mirandesa breed and 52 Crossbreds, with an average age of $10.1 \pm 2.32$ months, were slaughtered at one abattoir located in the Northeast of Portugal. Carcass temperature and $\mathrm{pH}$, logged during $24 \mathrm{~h}$ post-mortem, were modelled by exponential decay equations that estimated temperature $\left(k_{T}\right)$ and $\mathrm{pH}\left(k_{p H}\right)$ decay rates. Additionally, other $\mathrm{pH} /$ temperature descriptors were estimated from the fitted models. From linear models adjusted to each descriptor, it was found that hot carcass weight, age, breed, gender, age class, fat cover, conformation and transport and lairage time had influence $(\mathrm{P}<0.05)$ on $\mathrm{pH}$ and temperature decay rates. Thus, combining the variables $k_{T}$ and $k_{p H}$, and selected animal/carcass characteristics as linear predictors, a system to classify quality of carcasses was developed.
\end{abstract}

\section{Introduction}

In beef, the meat tenderness plays a major role in the consumers' overall eating satisfaction (Ferguson, 2004; Hopkins \& Geesink, 2009); albeit, meat tenderness is a complex trait affected by a variety of factors from animal's genotype up to the cooking process (Ferguson et al., 2001; Thompson, 2002). The interaction between the animal biological traits and pre- and post-slaughter environmental conditions has a tremendous impact on the biochemical processes that occur post-mortem as muscle is converted to meat and during storage (Lomiwes, Farouk, Wiklund, \& Young, 2014). In fact, Butchers, Ferguson, Devine, and Thompson (1998) showed that post-slaughter processing methods can double the meat shear force from 4.5 to $9.0 \mathrm{~kg}$.

The ultimate $p H$ is an important indicator of the meat quality (Thomson, Gardner, Simmons, \& Thompson, 2008; Kim, Warner, \& Rosenvold, 2014), however, during rigor mortis, the $p H$ and temperature of the muscle interact continuously (Hwang \& Thompson, 2001; Simmons et al., 2006; Hopkins et al., 2011; Hamoen, Vollebregt, \& van der Sman, 2013; Kahraman et al., 2012), since both affect the physical shortening (Tornberg, 1996; Thomson et al., 2008) and the proteolytic enzyme activity (Dransfield, 1992; Kim et al., 2014) thus it has been shown that this interaction impacts on the beef meat tenderness.

Under abattoir's chilling conditions, it can be expected considerable variation among carcasses in the pattern of $p H$ and temperature decline early post-mortem (Xavier, Gonzales-Barron, Muller, \& Cadavez, 2014), which will impact on meat tenderness. Carcasses with a slow $p H$ decline (or high $\mathrm{pH}$ at low temperature) are susceptible to cold-shortening leading to meat toughness, while the application of a high temperature treatment during early post-mortem period improves the meat tenderness (Whipple, Koohmaraie, Dikeman, \& Crouse, 1990). Yet, a very rapid $p H$ decline combined with a slow chilling regime also leads to an increase in meat toughness (Thomson et al., 2008), due to the exhaustion of alpha-calpain, reducing the meat ageing potential during chilling (Takahashi, Wang, Locher, \& Marsh, 1987). In fact, Hwang and Thompson (2001) showed that an intermediate $p H$ decline ( $p H 5.9$ to 6.2 at 1.5 hours post-mortem), or rigor temperature (29 to $30^{\circ} \mathrm{C}$ at $p H=6.0$ ) produced the most tender meat in the striploin muscle after 14 days of ageing. Hwang, Devine, and Hopkins (2003) showed that, in order to minimize the occurrence of cold-shortening the muscle temperature should not be lower than $11^{\circ} \mathrm{C}$ before the muscle $p H$ reaches $6.1-6.3$. This knowledge has led to the concept of $p H /$ temperature window (Hopkins, Ponnampalam, van de Ven, \& Warner, 2014), which describes the relationship between muscle $p H$ and temperature from slaughter to when the final $\mathrm{pH}$ is reached (Thompson, 2002; Ibarburu, Kliebenstein, \& Hueth, 2007; Hopkins et al., 2014; Anonymous, 2017). The ideal window requires the muscle $p H$ to be greater than 6.0 while

\footnotetext{
* Corresponding author at: CIMO Mountain Research Center, School of Agriculture, Polytechnic Institute of Braganza, Portugal.

E-mail address: vcadavez@ipb.pt (V.A.P. Cadavez).
} 
the carcass temperature is above $35^{\circ} \mathrm{C}$ and below 6.0 before the temperature falls below $12^{\circ} \mathrm{C}$. If the rate of $\mathrm{pH} /$ temperature decline does not fall through this ideal window, the meat tenderness is compromised, either by hot- or cold-shortening (Thompson, 2002; Anonymous, 2017).

Thus, the objective of this study was three-fold. The first objective was to model the decrease in temperature and $\mathrm{pH}$ during chilling of beef carcasses early post-mortem so that $\mathrm{pH}$ and temperature decline rates can be accurately estimated. The second objective was to evaluate the extent of influence of live-animal/carcass characteristics (i.e., sex, weight, age, breed, class, fat cover, conformation, and transport and lairage time) on the $\mathrm{pH}$ and temperature decline rates; or, otherwise, if the muscle shortening occurring during rigor mortis outweighs the effects of live-animal factors in determining carcass quality. Once the significant live-animal/carcass characteristics affecting $\mathrm{pH}$ and temperature decline were identified, linear discriminant analysis that classifies beef carcasses quality (i.e., tenderness) into optimal quality and cold-shortened were developed taking into account the ideal window rule.

\section{Material and methods}

\subsection{Beef animals}

A total of 126 beef animals, 85 males and 41 females, with an average age of $10.1 \pm 2.32$ months (74 crossbred and 52 Mirandesa breed) slaughtered at one abattoir located in the Northeast of Portugal were sampled. The animals were transported by truck to the abattoir; and, at arrival, they were kept in individual stalls until slaughtering. They were not fed but did receive water ad libitum. After stunning, animals were bled and dressed sequentially. Resulting carcasses had an average hot carcass weight (HCW) of $210 \pm 65.6 \mathrm{~kg}$. For each of the animals/carcasses, the following live-animal/carcass characteristics were annotated: sex, age, breed, transport time, lairage time, HCW, age class (calf, vealer or yearling), the SEUROP class from the European beef carcass classification scheme for conformation and degree of fat cover $(1,2,3$ or 4$)$.

\subsection{Temperature and $\mathrm{pH}$ recording}

After slaughter, $p H$ and temperature were recorded, in longissimus thoracis muscle at the level of the fourth rib, at intervals of $10 \mathrm{~min}$ during $24 \mathrm{~h}$ of carcass chilling. The $\mathrm{pH}$ and temperature measurements were taken using a weather-resistant wireless- transmitter CRISON pH probe (Crison Instruments SA, Barcelona, Spain) and wireless- transmitter OMEGA temperature probe Pt100 (Omega Engineering Limited, Manchester, United Kingdom) connected to an OMEGA UWTC-REC1 wireless channel receiver/host (Omega Engineering Limited, Manchester, United Kingdom).

\subsection{Statistical modelling}

\subsubsection{Fitting exponential decay models}

The experimental curves of $\mathrm{pH}$ and temperature decline post-mortem (p.m.) were modelled as a function of time using the parameterisation of the exponential decay function proposed by Hwang and Thompson (2001). The $p H$ decay was modelled using the three-parameter exponential decay function was defined as,

$p H(t)=p H_{0}+\left(p H_{0}-p H_{\infty}\right) \times \exp \left(-k_{p H} \times t\right)$

where $p H_{\infty}$ is the final $p H ; p H_{0}$ is the initial $p H ; k_{p H}$ is the exponential constant of $p H$ decay; and $t$ is the time in hours after slaughtering, using as time zero the time of slaughter. Similarly, for temperature the threeparameter model was defined as

$T(t)=T_{0}+\left(T_{0}-T_{\infty}\right) \times \exp (-k t \times t)$ where $T_{\infty}$ is the final temperature $\left({ }^{\circ} \mathrm{C}\right)$; $T_{0}$ is the initial temperature ( $\mathrm{C}$ ); and $k_{T}\left(\mathrm{~h}^{-1}\right)$ is the exponential constant of temperature decay. Eqs. 1 and 2 were fitted to each of the experimental decay curves originated from the 126 beef carcasses. Models' adequacy was assessed by examining residuals normality and heterocedasticity. Using the model parameters $\left(p H_{0}, p H_{\infty}, k_{p H}, T_{0}, T_{\infty}\right.$ and $\left.k_{T}\right)$, the following $p H /$ temperature decay descriptors were computed for each of the curves: the $p H$ at $1.5 \mathrm{~h}\left(\mathrm{pH}_{1.5}\right)$, at $3.0 \mathrm{~h}\left(\mathrm{pH}_{3.0}\right)$, at $4.5 \mathrm{~h}\left(\mathrm{pH}_{4.5}\right)$, at $6.0 \mathrm{~h}\left(\mathrm{pH}_{6.0}\right)$ and at $24.0 \mathrm{~h}\left(\mathrm{pH}_{24}\right)$; the temperature at $1.5 \mathrm{~h}\left(T_{15}\right)$, at $3.0 \mathrm{~h}\left(\mathrm{~T}_{3.0}\right)$, at $4.5 \mathrm{~h}$ $\left(T_{4.5}\right)$, and at $6.0 \mathrm{~h}\left(T_{6.0}\right)$; the time when $p H$ reached $6.0\left(t_{p H_{6.0}}\right)$, and the temperature at which $p H$ reached $6.0\left(t_{p H_{6.0}}\right)$ proposed by Hopkins et al. (2014).

\subsubsection{Effect of live-animal/carcass characteristics on $\mathrm{pH} /$ temperature} decay curve descriptors

In order to evaluate whether live-animal/carcass characteristics affect the pace at which $p H$ and temperature decline in a beef carcass early p.m., analyses of variance (ANOVA) were conducted separately on each of the temperature $/ \mathrm{pH}$ decay curve descriptors (namely, $\mathrm{pH}_{1.5}$, $p H_{3.0}, p H_{4.5}, p H_{6.0}, p H_{24}, T_{1.5}, T_{3.0}, T_{4.5}, t_{p H_{6.0}}, T p H_{6.0}, k_{p H}$ and $k_{T}$ ) as response variables with live-animal/carcass characteristics as explanatory variables. The animal/carcass characteristics considered as regressors were: sex, age, breed, HCW, transport time ( $t_{\text {Transport }}$ ), lairage time $\left(t_{\text {Lairage }}\right)$ and animal class (Class). Whenever a categorical factor (sex, breed or class) was significant $(P<0.10)$ in the ANOVA, leastsquares means were computed and contrasted among the factor levels. Because information on SEUROP classification and fat cover was not available for all 126 carcasses, but for 95 carcasses, a second run of ANOVAs was carried out on the data subset considering only SEUROP and fat cover as factors for all of the temperature/pH decay curve descriptors. As with the first ANOVA, least-squares means for SEUROP and fat cover levels were computed and contrasted when these factors turned out to be significant $(P<0.10)$.

\subsubsection{Carcass classification by quality compliance}

Taking into account the ideal window rule, an additional class variable named Compliance was created in the dataset to assign carcasses to one of two classes (i.e., cold-shortened "CS" and optimal quality "OQ") which were quality categories known a-priori from the experimental data. A carcass was classified as "OQ" if $T_{p H_{6.0}}$ was between 12 and $35^{\circ} \mathrm{C}$, and as "CS" if $T_{p H_{6.0}}$ was lower than 12 . In the 126 carcass dataset, since no carcass underwent hot-shortening (i.e., $T_{p H_{6.0}}$ was never higher than $35^{\circ} \mathrm{C}$ ), a third class "hot-shortened" could not be included. Thus, the problem reduced to predicting meat quality (either optimal or cold-shortened) from selected animal/carcass characteristics and $\mathrm{pH} /$ temperature decay descriptors.

As a first step, a principal component analysis was performed to the full data set in order to ascertain the variables (i.e., animal/carcass characteristics and $\mathrm{pH} /$ temperature decay descriptors) having the greatest capacity to discriminate between quality compliance classes. Once these variables were identified, a series of modelling functions for classification were tested and compared; namely: linear discriminant analysis (LDA), robust linear discriminant analysis (RLDA), k-nearest neighbours (kNN), support vector machines (SVM) and nearest shrunken centroids (NSC). The comparison was based on classification efficacy, and was accomplished by two different procedures:

1. Each of the classification models was trained using the entire data set. Distributions of model performance measures (accuracy and kappa statistics) were obtained by k-fold cross-validation resampling $(k=6)$ with 100 iterations. All the classification functions were set to select the tuning parameters with the largest value of the mean kappa statistic computed from the held-out samples;

2. Each of the classification models was trained using $\sim 70 \%$ of the data (89 samples) and was later used to generate predictions for new samples (remaining $\sim 30 \%$ of the data or 37 samples). Thus, a $\sim 70$ / 
$30 \%$ stratified random split of the data was first created. Models were then trained as described above, and tested using the separate data set to characterise their classification efficacy. Models' performance was characterised by obtaining confusion matrix, accuracy and kappa statistics. For further details on classification training and algorithms refer to Kuhn (2008).

Total accuracy is the sum of true positives and true negatives divided by the total number of items. The kappa statistic measures agreement relative to what would be expected by chance; hence a value of 1 indicates perfect agreement.

The package nlme (Pinheiro, Bates, DebRoy, Sarkar, \& Team, 2018) was used to fit the exponential decay models and the MAS $S$ package (Venables \& Ripley, 2002) was used to fit the linear models; principal component analysis was conducted using the FactoMineR package (Lê, Josse, \& Husson, 2008), and the classification training and testing using the caret package (from Jed Wing et al., 2018); all of them implemented in the software $\mathrm{R}$ (R Core Team, 2017). In addition, graphs were produced by the factoextra package (Kassambara \& Mundt, 2017).

\section{Results and discussion}

\subsection{Data description and modelled $\mathrm{pH}$ and temperature decay}

As beef carcasses in the abattoir were chosen randomly, the sample sizes across the animal/carcass characteristics' levels were different. Moreover, for some factors such as SEUROP and fat cover, data were not available for all classes: no beef animals with conformation "S" or "E" and with fat cover " 1 " or " 4 " were slaughtered in the abattoir (Table 1). Similarly, in terms of meat quality compliance, no carcass underwent hot-shortening, so the compliance classes that could be derived were "cold-shortened" and "optimal quality". From the data set, $\sim 39 \%$ of the monitored carcasses did not undergo an optimal $\mathrm{pH} /$ temperature decline, but had either a slow $\mathrm{pH}$ fall or a rapid temperature drop (Table 1).

The data description statistics for age and HCW by factor indicates that Mirandesa-breed animals were younger ( 9 months) and not as heavy (152 kg) as crossbred ones (10.5 months and $238 \mathrm{~kg}$; Table 1). As expected, heavier $(232 \mathrm{~kg}$ ) and older animals (11 months) were

Table 1

Mean ( \pm standard deviation) slaughter age, hot carcass weight by live-animal/ carcass characteristics.

\begin{tabular}{|c|c|c|c|c|}
\hline Characteristic $^{a}$ & Level & Sample size & Age (months) & $\begin{array}{l}\text { Hot carcass weight } \\
(\mathrm{kg})\end{array}$ \\
\hline \multirow[t]{2}{*}{ Gender } & Female & 41 & $9.8 \pm 2.12^{a}$ & $165 \pm 46.6^{a}$ \\
\hline & Male & 85 & $10.0 \pm 2.01^{a}$ & $221 \pm 62.8^{b}$ \\
\hline \multirow[t]{2}{*}{ Breed } & Crossbred & 74 & $10.5 \pm 2.10^{a}$ & $238 \pm 56.0^{a}$ \\
\hline & Mirandesa & 52 & $9.1 \pm 1.63^{b}$ & $152 \pm 30.9^{b}$ \\
\hline \multirow[t]{3}{*}{ Age class } & Calf & 30 & $7.8 \pm 0.42^{c}$ & $160 \pm 42.3^{c}$ \\
\hline & Vealer & 74 & $10.3 \pm 0.93^{b}$ & $215 \pm 57.5^{b}$ \\
\hline & Yearling & 22 & $14.2 \pm 1.42^{a}$ & $266 \pm 67.3^{a}$ \\
\hline \multirow[t]{2}{*}{ Fat class ${ }^{\mathrm{b}}$} & 2 & 43 & $10.3 \pm 1.76^{a}$ & $210 \pm 64.1^{a}$ \\
\hline & 3 & 41 & $11.0 \pm 2.03^{a}$ & $232 \pm 57.8^{a}$ \\
\hline \multirow[t]{4}{*}{ SEUROP $^{c}$} & $\mathrm{U}$ & 8 & $11.4 \pm 1.51^{a b}$ & $310 \pm 32.9^{a}$ \\
\hline & $\mathrm{R}$ & 31 & $11.1 \pm 2.18^{a}$ & $256 \pm 41.0^{b}$ \\
\hline & $\mathrm{O}$ & 33 & $10.6 \pm 1.95^{a b}$ & $204 \pm 53.2^{c}$ \\
\hline & $\mathrm{P}$ & 23 & $9.7 \pm 1.33^{b}$ & $161 \pm 27.3^{d}$ \\
\hline \multirow[t]{2}{*}{ Compliance $^{\mathrm{d}}$} & $\mathrm{CS}$ & 49 & $9.8 \pm 1.70^{a}$ & $190 \pm 53.0^{a}$ \\
\hline & OQ & 77 & $9.9 \pm 2.32^{a}$ & $211 \pm 68.6^{a}$ \\
\hline
\end{tabular}

a Means with different superscript letters differ significantly $(P<0.05)$.

b SEUROP fat class where 1 is Low, 2 is Slight, 3 is Average, 4 is High, and 5 is Very High.

c SEUROP conformation class where E is Excellent, $\mathrm{U}$ is Very Good, $\mathrm{R}$ is Good, $\mathrm{O}$ is Fair and $\mathrm{P}$ is Poor.

d Carcass quality compliance where CS is Cold-shortened and OQ is Optimum quality carcasses.
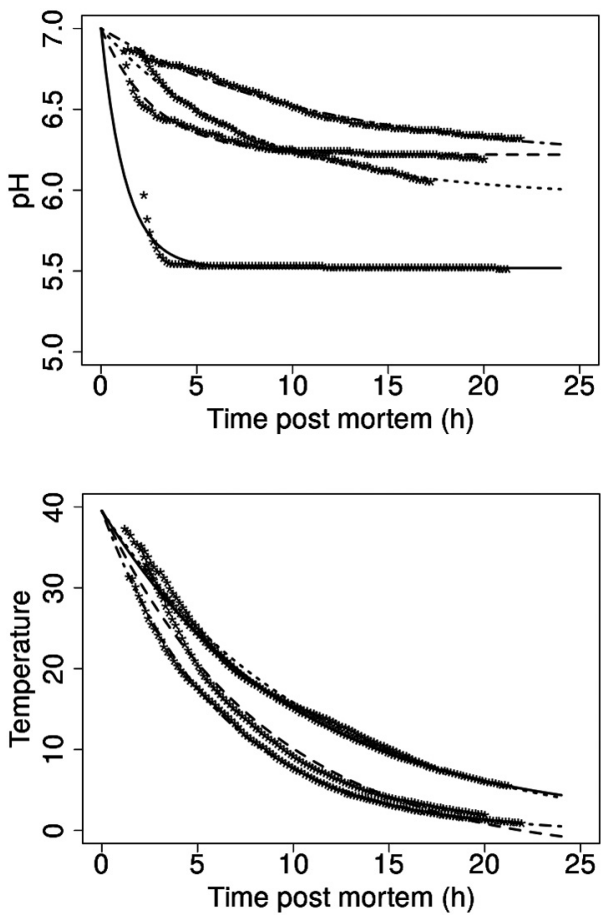

Fig. 1. $\mathrm{pH}$ (top) and temperature (bottom) decline experimental curves from four sampled carcasses showing fitted exponential models in dashed lines.

associated to greater fat cover (class " 3 "). While heavier carcasses (221 kg) belonged to male animals, the data also showed that higher SEUROP conformation classes were assigned to older and heavier animals. Thus, the live-animal/carcass characteristics measured and extracted from the abattoir's records were highly interrelated.

All of the $\mathrm{pH}$ and temperature experimental curves obtained from the 126 carcasses could be closely depicted by the chosen exponential decay models. There were no convergence problems and residuals from each model could be approximated to normal distributions. Even the experimental $\mathrm{pH}$ decay curves from beef muscles that did not reach the rigor mortis $\mathrm{pH}(\mathrm{pH}>6.0)$ within the 24-h monitored period, which amounted to 36 out of 126 curves, were well adjusted by the model. For illustration, three of these curves are shown in Fig. 1 (top). Notice also that both $\mathrm{pH}_{0}$ and $T_{0}$ were fixed, respectively, at 7.0 (Fig. 1, top) and $39.0^{\circ} \mathrm{C}$ (Fig. 2, bottom) at time zero, which represented the time of slaughter in the models. $p H_{0}$ (Eq. 1) and $T_{0}$ (Eq. 2) were not estimated as models' parameters because many experimental decay curves produced unrealistic estimates of $\mathrm{pH}_{0}(>7.0)$ and $\mathrm{T}_{0}\left(>40^{\circ} \mathrm{C}\right)$ which in turn led to poorer goodness-of-fit measures. Generally, fitting the exponential decay functions with known $p H_{0}$ and $T_{0}$ provided a useful means of describing $\mathrm{pH}$ and temperature changes up to $24 \mathrm{~h}$ post-mortem

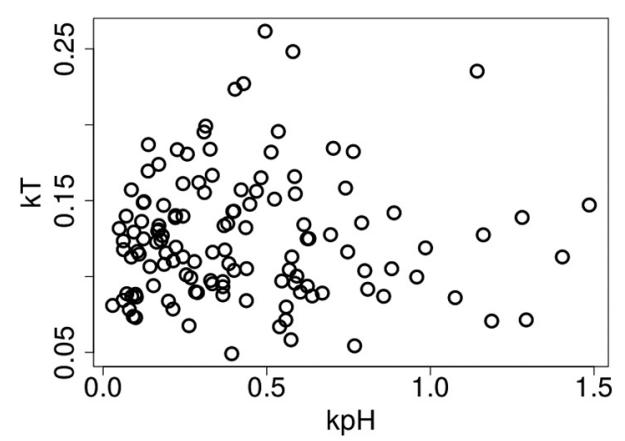

Fig. 2. Lack of association between $p H\left(k_{p H}\right)$ and temperature $\left(k_{T}\right)$ exponential decay rates. 
Table 2

Mean, median and range of $p H$ and temperature decline descriptors.

\begin{tabular}{lllll}
\hline Descriptors $^{\mathrm{a}}$ & Mean & Median & Minimum & Maximum \\
\hline$p H_{1.5}$ & 6.52 & 6.53 & 6.01 & 6.93 \\
$p H_{3.0}$ & 6.24 & 6.25 & 5.62 & 6.87 \\
$p H_{4.5}$ & 6.08 & 6.07 & 5.45 & 6.81 \\
$p H_{6.0}$ & 6.00 & 5.95 & 5.38 & 6.76 \\
$p H_{24}$ & 5.78 & 5.74 & 5.30 & 6.51 \\
$T_{1.5}$ & 32.9 & 33.1 & 27.2 & 36.4 \\
$T_{3.0}$ & 27.8 & 28.0 & 19.2 & 33.9 \\
$T_{4.5}$ & 23.7 & 23.7 & 13.8 & 31.5 \\
$T_{6.0}$ & 20.1 & 20.1 & 10.1 & 29.3 \\
$k_{p H}$ & 0.335 & 0.344 & 0.079 & 0.697 \\
$k_{T}$ & 0.113 & 0.101 & 0.022 & 0.256 \\
$t_{p H_{6.0}}$ & 4.9 & 3.9 & 1.5 & 20.2 \\
$T_{p H_{6.0}}$ & 24.4 & 25.7 & 1.96 & 35.0 \\
\hline
\end{tabular}

${ }^{\text {a }} k_{p H}\left(\mathrm{~h}^{-1}\right)$ is the exponential constant of $\mathrm{pH}$ decay; $k_{T}(\mathrm{C} C)$ is the exponential constant of temperature decay; $\mathrm{pH}_{1.5}$ is the $\mathrm{pH}$ at 1.5 hours; $\mathrm{pH}_{3.0}$ is the $\mathrm{pH}$ at $3.0 \mathrm{~h} ; \mathrm{pH}_{4.5}$ is the $\mathrm{pH}$ at 4.5 hours; $\mathrm{pH}_{6.0}$ is the $\mathrm{pH}$ at 6.0 hours; $\mathrm{pH}_{24}$ is the $\mathrm{pH}$ at $24 \mathrm{~h} ; T_{1.5}\left({ }^{\circ} \mathrm{C}\right)$ is the temperature at 1.5 hours; $T_{3.0}\left({ }^{\circ} \mathrm{C}\right)$ is the temperature at $3.0 \mathrm{~h} ; T_{4.5}(\mathrm{C})$ is the temperature at $4.5 \mathrm{~h} ; T_{6.0}(\mathrm{C})$ is the temperature at 6.0 hours; $t_{p H_{6.0}}$ (hours) is the time when $\mathrm{pH}$ reached $6.0 ; T_{p H_{6.0}}\left({ }^{\circ} \mathrm{C}\right)$ is the temperature at which $\mathrm{pH}$ reached 6.0.

\section{(Fig. 1).}

Descriptive statistics of the $p H$ and temperature decay descriptors (models' fitted parameters and estimated values) are compiled in Table 2. Sampled muscles' $p H$ decreased steadily from $\sim 7.0$ to median values of $6.53,6.25,6.07$ and 5.95 , at the corresponding median temperatures of $33.1,28.0,23.7$ and $20.1{ }^{\circ} \mathrm{C}$ after $1.5,3.0,4.5$ and 6 hours p.m., respectively (Table 2 ). In the sampled carcasses, on average, monitored muscles attained the $\mathrm{pH}$ of 6.0 after $6 \mathrm{~h}$ (see $p H_{6.0}$ ). Nonetheless, wide ranges in muscle $p H$ and temperature values were obtained at each sampling time, as shown in Fig. 1 and Table 2. The variation (i.e., range) in $\mathrm{pH}$ and temperature at different sampling times presented a tendency to increase as time elapsed (Table 2). As a consequence, the estimated time to reach rigor mortis was highly variable, ranging from 1.52 to 20.2 hours; although 36 carcasses did not attain $p H=6.0$ by the end of the $24 \mathrm{~h}$ recorded period). Similarly, the rigor temperature $\left(T_{p H_{60}}\right)$ had a wide range between 1.96 and $35.0^{\circ} \mathrm{C}$. Contrasting this finding with the ideal window rule (viz. muscle should reach rigor while in the temperature range $12-35^{\circ} \mathrm{C}$ ), it can be deduced that, whereas both phenomena hot- and cold-shortening are likely to occur in the beef meat produced in the commercial abattoir surveyed, cold-shortening takes place at a much higher frequency. Only a proportion of $\sim 61 \%$ of the sampled carcasses exhibited an optimal $\mathrm{pH} /$ temperature decay for becoming meat of good eating quality. From our data, the ultimate $\mathrm{pH}\left(\mathrm{pH}_{24}\right)$ median was 5.74 , a value very close to the maximum final $\mathrm{pH}\left(5.30<\mathrm{pH}_{24}<5.70\right)$ recommended by Meat Standards Australia (Anonymous, 2017). Moreover, a high proportion $(\sim 29 \%)$ of the sampled muscles reached an ultimate $p H$ above 6.0 (see maximum value of $\mathrm{pH}_{24}=6.51$ in Table 2), implying that these carcasses would be cold-shortened and tough, as for $\mathrm{pH}_{24}>6.0$, the drip loss is constant and minimal (Hamoen, Vollebregt, \& van der Sman, 2013). Ultimate $p H$ of meat is a major quality determinant since it has been demonstrated to explain 79 of the variation in meat colour, $57 \%$ of the variation in drip loss, and $77 \%$ of the variation in purge loss (Bidner et al., 2004).

The considerable carcass-to-carcass variation in $p H$ and temperature decay under commercial conditions can be also appreciated from the wide range of the fitted slopes $k_{p H}(0.079-0.6971 / h)$ and $k_{T}$ $\left(0.022-0.2561^{\circ} \mathrm{C} / \mathrm{h}\right.$; Table 2$)$. All the studied live-animal/carcass characteristics were found to affect the rate of temperature decline $\left(k_{T}\right)$ while for the $p H$ decay rate $\left(k_{p H}\right)$, gender, breed and fat class had no discernible effect (Table 3). In the sampled beef muscles, no correlation was found between $p H\left(k_{p H}\right)$ and temperature $\left(k_{T}\right)$ decay rates $(r=0.10$; Table 4$)$, which corroborated earlier results in electrically-
Table 3

Mean ( \pm standard error) of fitted $\mathrm{pH}\left(k_{p H}\right)$ and temperature $\left(k_{T}\right)$ decay rates by live-animal/carcass characteristics.

\begin{tabular}{llll}
\hline Characteristic $^{\mathrm{a}}$ & Level & $k_{p H}$ & $k_{T}$ \\
\hline Gender & Female & $0.335 \pm 0.0229^{a}$ & $0.124 \pm 0.0077^{a}$ \\
& Male & $0.334 \pm 0.0146^{a}$ & $0.108 \pm 0.0059^{a}$ \\
Breed & Crossbred & $0.339 \pm 0.0165^{a}$ & $0.085 \pm 0.0041^{b}$ \\
& Mirandesa & $0.328 \pm 0.0186^{a}$ & $0.152 \pm 0.0070^{a}$ \\
Age class & Calf & $0.367 \pm 0.0199^{a}$ & $0.141 \pm 0.0078^{a}$ \\
& Vealer & $0.308 \pm 0.0171^{b}$ & $0.105 \pm 0.0059^{b}$ \\
& Yearling & $0.371 \pm 0.0306^{a b}$ & $0.072 \pm 0.0109^{c}$ \\
Fat class & & $0.322 \pm 0.0232^{a}$ & $0.117 \pm 0.0074^{a}$ \\
& 2 & $0.323 \pm 0.0193^{a}$ & $0.084 \pm 0.0055^{b}$ \\
SEUROP & & $0.453 \pm 0.0314^{a}$ & $0.058 \pm 0.0071^{c d}$ \\
& $\mathrm{U}$ & $0.306 \pm 0.0223^{b}$ & $0.074 \pm 0.0082^{c}$ \\
& $\mathrm{R}$ & $0.317 \pm 0.0619^{b}$ & $0.106 \pm 0.0051^{b}$ \\
& $\mathrm{O}$ & $0.298 \pm 0.0203^{b}$ & $0.145 \pm 0.0098^{a}$ \\
Compliance $^{\mathrm{d}}$ & $\mathrm{P}$ & $0.241 \pm 0.0172^{b}$ & $0.121 \pm 0.0069^{a}$ \\
& $\mathrm{CS}$ & $0.394 \pm 0.0130^{a}$ & $0.108 \pm 0.0064^{a}$
\end{tabular}

${ }^{\text {a }}$ Means with different superscript letters differ significantly $(P<0.05)$.

b SEUROP fat class where 1 is Low, 2 is Slight, 3 is Average, 4 is High, and 5 is Very High.

c SEUROP conformation class where E is Excellent, $\mathrm{U}$ is Very Good, $\mathrm{R}$ is Good, O is Fair and P is Poor.

d Carcass quality compliance where CS is Cold-shortened and OQ is Optimum quality carcasses.

stimulated beef carcasses (Hwang \& Thompson, 2001). The fact that these decay rates are randomly distributed and independent (Fig. 2) is advantageous from a statistical modelling viewpoint since they can be used as orthogonal (i.e., independent) variables in the development of a multivariate algorithm for carcass quality classification.

From the correlation matrix analysis (Table 4), it was deduced that $\mathrm{pH}_{3.0}$ was a descriptor suitable for inclusion in the classification analysis because it contains information of both rigor time and rigor temperature (correlation of 0.86 with $t_{p H_{6.0}}$, and -0.83 with $T_{p H_{6.0}}$; the ultimate $\mathrm{pH}$ of the carcass (correlation of 0.83 with $p \mathrm{H}_{24}$ ); and the $p H$ decay rate (correlation of -0.84 with $k_{p H}$ ). Thus, $\mathrm{pH}_{3.0}$ descriptor represents a measurement that, although taken earlier during chilling, can predict with good accuracy the remaining $p H$ decline trend and the ultimate $p H$. In a similar fashion, the muscle temperature after $3 \mathrm{~h} \mathrm{p} . \mathrm{m}$. $\left(T_{3.0}\right)$ is a suitable descriptor for inclusion in the classification analysis, because, despite taken very early during carcass monitoring, it contains most of the information of the temperature decline rate (correlation of -0.98 with $k_{T}$ ).

\subsubsection{Effect of live-animal/carcass characteristics on $\mathrm{pH} /$ temperature} decay curve descriptors

In the analyses of variance for the $p H$ estimates at different time points, $p H_{1.5}, \mathrm{pH}_{3.0}, \mathrm{pH}_{4.5}, \mathrm{pH}_{6.0}$ and $\mathrm{pH}_{24}$, the variables related to animal size - hot carcass weight (HCW), age class and SEUROP - were consistently significant (Table 4). The inverse relationship between carcass weight and $\mathrm{pH}$ at the different times (as indicated by the negative regression coefficients -0.001 in Table 4) suggests that a heavier beef carcass can be associated to higher muscle glycogen reserves, which in turn prompts a faster $p H$ drop. The same explanation applies to the SEUROP variables, whereby beef carcasses of increasingly better conformation (from "P" to "U") attained progressively lower $p H$ values. For instance, after 1.5 hours p.m. $\left(\mathrm{pH}_{1.5}\right)$, carcasses classified as "U" attained on average a $p H$ of 6.359 , whilst "P" carcasses had still a $p H$ of 6.587 (Table 4). The same trend in least-squares mean estimates for conformation classes was observed in the subsequent time points $\mathrm{pH}_{3.0}$, $p H_{4.5}, \mathrm{pH}_{6.0}$ and $\mathrm{pH}_{24}$. Age class displayed also some effect on the estimated $p H$ values: younger animals (calves) consistently reached lower $p H$ values than vealers and yearlings at all time points. For instance, the mean final $p H\left(\mathrm{pH}_{24}\right)$ of calves was 5.651 which was lower $(P<0.05)$ than those of vealers (5.846) and yearlings (5.865; Table 4). This result 
Table 4

Correlation matrix of selected $\mathrm{pH} /$ temperature descriptors and model parameters.

\begin{tabular}{|c|c|c|c|c|c|c|c|c|c|}
\hline Descriptors $^{\mathrm{a}}$ & $\mathrm{pH}_{3.0}$ & $p H_{4.5}$ & $\mathrm{pH}_{24}$ & $T_{3.0}$ & $T_{4.5}$ & $k_{p H}$ & $k_{T}$ & $t_{p H_{6.0}}$ & $T_{p H_{6,0}}$ \\
\hline$p H_{3.0}$ & 1.00 & & & & & & & & \\
\hline $\mathrm{pH}_{4.5}$ & 0.99 & 1.00 & & & & & & & \\
\hline $\mathrm{pH}_{24}$ & 0.83 & 0.88 & 1.00 & & & & & & \\
\hline$T_{3.0}$ & 0.13 & 0.14 & 0.18 & 1.00 & & & & & \\
\hline$T_{4.5}$ & 0.12 & 0.13 & 0.17 & 0.99 & 1.00 & & & & \\
\hline$k_{p H}$ & -0.84 & -0.78 & -0.42 & -0.09 & -0.08 & 1.00 & & & \\
\hline$k_{T}$ & -0.15 & -0.16 & -0.20 & -0.98 & -0.98 & 0.10 & 1.00 & & \\
\hline$t_{p H_{6,0}}$ & 0.86 & 0.88 & 0.78 & 0.15 & 0.15 & -0.68 & -0.17 & 1.00 & \\
\hline$T_{p H_{6.0}}$ & -0.83 & -0.84 & -0.72 & 0.32 & 0.33 & 0.66 & -0.29 & -0.85 & 1.00 \\
\hline
\end{tabular}

${ }^{\text {a }} k_{p H}\left(\mathrm{~h}^{-1}\right)$ is the exponential constant of $\mathrm{pH}$ decay; $k_{T}(\mathrm{C})$ is the exponential constant of temperature decay; $\mathrm{pH}_{3.0}$ is the $\mathrm{pH}$ at 3.0 hours; $\mathrm{pH}_{4.5}$ is the $\mathrm{pH}$ at 4.5

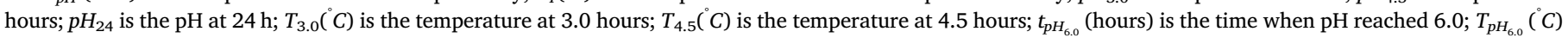
is the temperature at which $\mathrm{pH}$ reached 6.0; $|r|>0.18$ is significant $(p<0.05)$.

was unexpected as younger animals tend to have higher $p H$ values, and more likely to lead to DFD meat due to the fact that they have increased energy requirements, and they are more difficult to adapt to the effects caused by stress. Nonetheless, previous works (Sánchez, Monserrat, Brea, Dios, \& Iglesias, 1997; McGeehin, Sheridan, \& Butler, 2001) were also faced with higher $p H$ values in older animal carcasses. There is no strong evidence that adult animals have lower $p H$ values, although it is known that the muscle glycogen content and $p H$ drop rate increase with the age of the animal. The buffer capacity of the muscles and their water retention capacity also influence the value of ultimate $p H$.

As with the $p H$ estimates at the different time points, both SEUROP conformation and age class influenced the $p H$ decay rate $\left(k_{p H}\right)$. The conformation class " $\mathrm{U}$ " produced higher rates of $\mathrm{pH}$ decline $(p=0.008)$, while the vealers as a group presented a slower $p H$ decay $\left(p=0.025\right.$; Table 5). The numerically higher value of $k_{p H}(0.371)$ for the yearlings $(12-24$ month-aged) can be explained by the fact that this category includes also females, which due to their likely greater size and glycogen reserves are associated to a faster decay in $\mathrm{pH}$. On the contrary, carcasses of poorer conformation corresponding to class "P" exhibited the (at least numerically) slowest decay in $p H\left(k_{p H}=0.298\right)$.

Unlike the $p H$-related descriptors, in addition the variables breed, gender and fat cover affected the temperature-related descriptors. Age (as a continuous variable) and transport time, nonetheless, could not be proven to be relevant in any of the $\mathrm{pH}$ or temperature decay descriptors. In the case of temperature decay rate $\left(k_{T}\right)$, once again animal characteristics related to animal size such as HCW $(p<0.0001)$, breed $(p=0.043)$, gender $(p=0.108)$, fat cover $(p<.0001)$ and SEUROP $(p<0.0001)$ greatly determined the rate of temperature decay in the monitored muscle samples (Table 5). HCW (slope estimate -0.001) and fat cover (slope estimate-0.029) were inversely correlated with temperature decay rate because, in smaller animals, heat is more rapidly liberated and, in addition, heat transfer does not get slowed down by greater fat levels. Fatter carcasses $(0.080)$ had a lower $(p<0.05)$ temperature decay rate than leaner carcasses (0.109). Such retarding effect of fat on heat transfer became more evident in the linear models for carcass temperature at different time points. Carcasses of fat cover " 2 " reached lower temperatures $\left(28.2,24.0\right.$ and $\left.20.3^{\circ} \mathrm{C}\right)$ than those of greater fat cover " 3 " ( $29.9,26.2$, and $\left.22.9^{\circ} \mathrm{C}\right)$ after $3.0,4.5$ and $6.0 \mathrm{~h}$, respectively, following slaughter. Said otherwise, a fatter carcass requires longer time to reach the lower temperature that a leaner carcass would reach at the same time point. Carcasses of Mirandesa-breed origin cooled down significantly faster $\left(k_{T}=0.122\right)$ than those of

Table 5

Estimates of live-animal/carcass characteristics as significant explanatory variables in the linear models fitted to $\mathrm{pH}$ measured at $3.0\left(\mathrm{pH}_{3.0}\right), 4.5\left(\mathrm{pH}_{4.5}\right)$ and $24\left(\mathrm{pH}_{24}\right)$ hours post slaughter.

\begin{tabular}{|c|c|c|c|c|c|c|}
\hline \multirow[t]{2}{*}{ Animal/carcass characteristics ${ }^{\mathrm{a}}$} & \multicolumn{2}{|l|}{$p H_{3.0}$} & \multicolumn{2}{|l|}{$p H_{4.5}$} & \multicolumn{2}{|l|}{$\mathrm{pH}_{24}$} \\
\hline & Mean \pm SEM & $P>|t|$ & Mean \pm SEM & $P>|t|$ & Mean \pm SEM & $P>|t|$ \\
\hline HCW & $-0.001 \pm 0.0005$ & 0.036 & $-0.001 \pm 0.0006$ & 0.028 & $-0.001 \pm 0.0005$ & 0.008 \\
\hline \multicolumn{7}{|l|}{ Class } \\
\hline Vealer & $0.206 \pm 0.0690$ & 0.004 & $0.231 \pm 0.0762$ & 0.003 & $0.195 \pm 0.0686$ & 0.005 \\
\hline Yearling & $0.149 \pm 0.1137$ & 0.193 & $0.176 \pm 0.1250$ & 0.162 & $0.213 \pm 0.1127$ & 0.061 \\
\hline \multicolumn{7}{|l|}{ SEUROP } \\
\hline $\mathrm{O}$ & $-0.035 \pm 0.0904$ & 0.696 & $-0.038 \pm 0.1005$ & 0.707 & $-0.006 \pm 0.0905$ & 0.940 \\
\hline $\mathrm{R}$ & $-0.072 \pm 0.0916$ & 0.436 & $-0.085 \pm 0.1018$ & 0.407 & $-0.071 \pm 0.0917$ & 0.440 \\
\hline $\mathrm{U}$ & $-0.296 \pm 0.1366$ & 0.033 & $-0.306 \pm 0.1518$ & 0.047 & $-0.213 \pm 0.1368$ & 0.100 \\
\hline \multicolumn{7}{|c|}{ 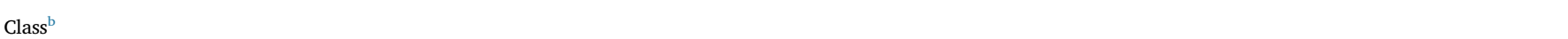 } \\
\hline Calf & $6.110 \pm 0.0548^{a}$ & - & $5.933 \pm 0.0604^{a}$ & - & $5.651 \pm 0.0544^{a}$ & - \\
\hline Vealer & $6.317 \pm 0.0385^{b}$ & - & $6.165 \pm 0.0423^{b}$ & - & $5.846 \pm 0.0381^{b}$ & - \\
\hline Yearling & $6.259 \pm 0.0916^{a b}$ & - & $6.110 \pm 0.1008^{a b}$ & - & $5.865 \pm 0.0908^{b}$ & - \\
\hline \multicolumn{7}{|l|}{ SEUROP $^{\mathrm{c}}$} \\
\hline $\mathrm{P}$ & $6.343 \pm 0.0694^{a}$ & - & $6.194 \pm 0.0771^{a}$ & - & $5.864 \pm 0.0695^{a}$ & - \\
\hline $\mathrm{O}$ & $6.308 \pm 0.0579^{a}$ & - & $6.156 \pm 0.0644^{a}$ & - & $5.857 \pm 0.0580^{a}$ & - \\
\hline $\mathrm{R}$ & $6.272 \pm 0.0598^{a}$ & - & $6.109 \pm 0.0664^{a b}$ & - & $5.793 \pm 0.0598^{a b}$ & - \\
\hline $\mathrm{U}$ & $6.047 \pm 0.1180^{b}$ & - & $5.889 \pm 0.1307^{a}$ & - & $5.651 \pm 0.1178^{b}$ & - \\
\hline
\end{tabular}

${ }^{\text {a }}$ Model estimates, standard errors and $P$-values are shown only for animal/carcass characteristics that were significant in the ANOVA (Pr(F) $<0.10$ ).

b Least-squares means and standard errors of factor levels were computed only when categorical variables (i.e, breed, gender, fat, class) were significant in the ANOVA.

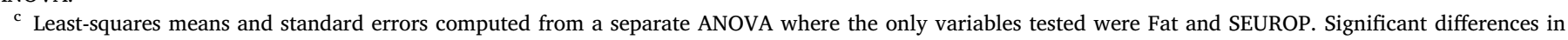
means are denoted by different superscript letters within a factor. 
crossbred (0.102) as they were slaughtered at a younger age (i.e., smaller carcasses). Similarly, as female animals were overall larger than male ones, the mean temperature decay rate in females was lower (0.105). The temperature decay was also slower in carcasses having better conformation (from "P" to "U") and in those from older animals (from "calf" to "yearling").

As with $k_{T}$, HCW, breed, gender, class, fat and SEUROP conformation consistently moderated the carcass temperature after 1.5, 3.0, 4.5 and 6.0 hours p.m. Since female animals are associated to greater carcass size and fat deposits than males, following the reasoning above, it is not unexpected that recorded muscles samples from females presented higher mean temperatures than the ones from males (notice that least-square mean estimates for $T_{1.5}, T_{3.0}, T_{4.5}$ and $T_{6.0}$ for females are systematically higher than for males; Table 3). Carcasses of greater conformation and higher age class (i.e., heavier carcasses) presented higher mean temperatures at the different time points, $T_{1.5}, T_{3.0}, T_{4.5}$ and $T_{6.0}$. For instance, $3 \mathrm{~h}$ after slaughter, calves, vealer and yearlings cooled down up to a mean of $26.5,27.6$ and $29.0^{\circ} \mathrm{C}$, respectively; while the conformation classes "P", "O", "R" and "U" attained consistentlyincreasing mean temperatures of $26.3,28.1,30.1$ and $31.6^{\circ} \mathrm{C}$, respectively, in the sampled muscle (Table 6). Unexpectedly, lairage time was positively associated to the carcass temperature at the different time points ( $p=0.019-0.090)$. This could have been rather an effect of the abattoir logistics of slaughtering smaller animals first.

In the linear models for the descriptors related to rigor mortis, the only variable that statistically influenced the time to reach $p H_{6.0}$ was the fat cover, although at a significance level of $20 \%$. The smaller carcasses of animals aged between $8-12$ months, took the longest to attain rigor mortis $\left(t_{p H_{6.0}}=5.39 \mathrm{~h}\right)$, because smaller carcasses may be associated to lower glycogen levels, which retards $p H$ drop. Contrarily, carcasses from animals aged $12-24$ months took on average a significantly shorter time to reach rigor mortis $\left(t_{p H_{6.0}}=4.75 \mathrm{~h}\right)$. The thickness of the subcutaneous fat has an important role, since it acts as a thermal insulator, protecting the muscles of adverse effects of direct exposure to cooling temperatures. It also allows the muscles to have a slower cooling and optimises the proteolytic enzyme activity, reducing the likelihood of cold-shortening and improving meat tenderness (Zhou, $\mathrm{Xu}, \&$ Liu, 2010). Ferguson et al. (2001) stated that carcasses with fat thickness between 3 and 4 have adequate capacity to achieve the rigor mortis and are less likely to suffer the phenomenon of cold-shortening. Fat cover associated with the degree of finish has a very positive impact on the beef quality characteristics (tenderness, colour, flavour and juiciness), and consequently, on the quality profile of the final product (Kinsella, Sheridan, \& Rowe, 2006).

The carcass temperature at rigor mortis $\left(T_{p H_{6.0}}\right)$ was influenced by the hot carcass weight, the age class and the SEUROP conformation. The positive coefficient with carcass weight (0.039; Table 6) implies that in heavier carcasses, the $\mathrm{pH}$ drops faster while temperature is still high, in comparison to lighter carcasses where $p H$ drops at a slower rate while they get cooler. The same reasoning can be applied to age class: the larger carcasses from yearlings reached rigor mortis at a mean temperature of $29.1^{\circ} \mathrm{C}$, significantly higher than rigor temperature of the

Table 6

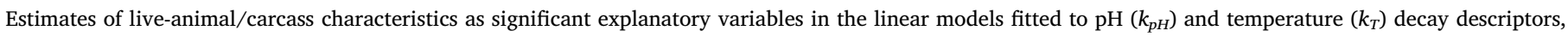
time at $p H=6.0\left(t_{p H_{6.0}}\right)$ and carcass temperature at $p H=6.0\left(T_{p H_{6.0}}\right)$.

\begin{tabular}{|c|c|c|c|c|c|c|c|c|}
\hline \multirow[t]{2}{*}{ Animal/carcass characteristics ${ }^{\mathrm{a}}$} & \multicolumn{2}{|l|}{$k_{p H}$} & \multicolumn{2}{|l|}{$k_{T}$} & \multicolumn{2}{|l|}{$t_{p H_{6.0}}$} & \multicolumn{2}{|l|}{$T_{p H_{6.0}}$} \\
\hline & Mean \pm SEM & $P>|t|$ & Mean \pm SEM & $P>|t|$ & Mean \pm SEM & $P>|t|$ & Mean \pm SEM & $P>$ \\
\hline HCW & - & - & $-0.001 \pm 0.0001$ & 0.0001 & - & - & $0.039 \pm 0.0146$ & 0.009 \\
\hline Breed-Mirandesa & - & - & $0.020 \pm 0.0097$ & 0.043 & - & - & - & - \\
\hline Gender-Male & - & - & $0.014 \pm 0.0085$ & 0.108 & - & - & - & - \\
\hline \multicolumn{9}{|l|}{ Class $^{\mathrm{b}}$} \\
\hline Vealer & $-0.058 \pm 0.0266$ & 0.025 & $-0.012+0.0078$ & 0.877 & & & $-2.160+1.8907$ & 0.410 \\
\hline Yearling & $0.004 \pm 0.0421$ & 0.297 & $-0.028 \pm 0.0133$ & 0.831 & & & $0.332 \pm 3.2032$ & 0.910 \\
\hline Fat-3 & - & - & $-0.029 \pm 0.0070$ & 0.0001 & - & - & - & - \\
\hline \multicolumn{9}{|l|}{ SEUROP } \\
\hline $\mathrm{O}$ & $0.018 \pm 0.0378$ & 0.624 & $-0.037 \pm 0.0094$ & 0.0001 & - & - & $3.620 \pm 2.6400$ & 0.176 \\
\hline $\mathrm{R}$ & $0.008 \pm 0.0383$ & 0.832 & $-0.066 \pm 0.0095$ & 0.0001 & - & - & $6.370 \pm 2.5600$ & 0.0016 \\
\hline $\mathrm{U}$ & $0.155 \pm 0.0571$ & 0.008 & $-0.088 \pm 0.0141$ & 0.0001 & - & - & $7.200 \pm 3.500$ & 0.044 \\
\hline \multicolumn{9}{|l|}{ Breed $^{\mathrm{b}}$} \\
\hline Crossbred & - & - & $0.102 \pm 0.0055^{a}$ & - & - & - & - & - \\
\hline Mirandesa & - & - & $0.122 \pm 0.0072^{b}$ & - & - & - & - & - \\
\hline \multicolumn{9}{|l|}{ Gender $^{\mathrm{b}}$} \\
\hline Female & - & - & $0.105 \pm 0.0068^{a}$ & - & - & - & - & - \\
\hline Male & - & - & $0.119 \pm 0.0050^{b}$ & - & - & - & - & - \\
\hline \multicolumn{9}{|l|}{ Class $^{\mathrm{b}}$} \\
\hline Calf & $0.367 \pm 0.0212^{a}$ & & $0.134 \pm 0.0064^{a}$ & - & - & - & - & - \\
\hline Vealer & $0.309 \pm 0.0161^{b}$ & & $0.118 \pm 0.0052^{b}$ & - & - & - & - & - \\
\hline Yearling & $0.371 \pm 0.0363^{a b}$ & & $0.095 \pm 0.011^{c}$ & - & - & - & - & - \\
\hline \multicolumn{9}{|l|}{ Fat $^{\mathrm{b}}$} \\
\hline 2 & - & - & $0.109 \pm 0.0053^{a}$ & - & $4.518 \pm 0.8060^{a}$ & - & - & - \\
\hline 3 & - & - & $0.080 \pm 0.0057^{b}$ & - & $5.896 \pm 0.7315^{b}$ & - & - & - \\
\hline \multicolumn{9}{|l|}{ SEUROP $^{c}$} \\
\hline $\mathrm{P}$ & $0.298 \pm 0.0290^{a}$ & - & $0.143 \pm 0.0072^{a}$ & - & - & - & - & - \\
\hline $\mathrm{O}$ & $0.316 \pm 0.0242^{a}$ & - & $0.105 \pm 0.0061^{b}$ & - & - & - & - & - \\
\hline $\mathrm{R}$ & $0.306 \pm 0.0250^{a}$ & - & $0.076 \pm 0.0063^{c d}$ & - & - & - & - & - \\
\hline $\mathrm{U}$ & $0.453 \pm 0.0492^{b}$ & - & $0.055 \pm 0.0121^{d}$ & - & - & - & - & - \\
\hline
\end{tabular}

${ }^{\text {a }}$ Model estimates, standard errors and P-values are shown only for animal/carcass characteristics that were significant in the ANOVA (Pr(F) $<0.10$ ).

b Least-squares means and standard errors of factor levels were computed only when categorical variables (i.e, breed, gender, class, fat) were significant in the ANOVA.

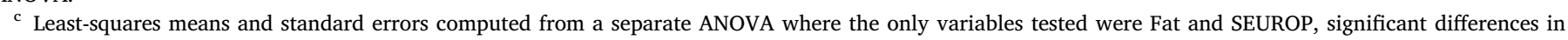
means are denoted by different superscript letters within a factor. 
Table 7

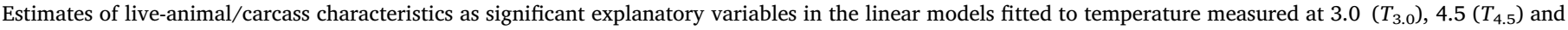
$6.0\left(T_{6.0}\right)$ hours post-slaughter.

\begin{tabular}{|c|c|c|c|c|c|c|}
\hline \multirow[t]{2}{*}{ Animal/carcass characteristics ${ }^{a}$} & \multicolumn{2}{|l|}{$T_{3.0}$} & \multicolumn{2}{|l|}{$T_{4.5}$} & \multicolumn{2}{|l|}{$T_{6.0}$} \\
\hline & Mean \pm SEM & $P>|t|$ & Mean \pm SEM & $P>|t|$ & Mean \pm SEM & $P>|t|$ \\
\hline HCW & $0.036 \pm 0.0056$ & $<0.0001$ & $0.045 \pm 0.0 .0068$ & $<0.0001$ & $0.052 \pm 0.0053$ & $<0.0001$ \\
\hline Breed-Mirandesa & $-0.568 \pm 0.5816$ & 0.330 & $-0.521 \pm 0.7063$ & 0.460 & - & - \\
\hline Gender-Male & $-0.862 \pm 0.5103$ & 0.094 & $-1.025 \pm 0.6200$ & 0.100 & $-1.215 \pm 0.6060$ & 0.047 \\
\hline \multicolumn{7}{|l|}{ Class $^{\mathrm{b}}$} \\
\hline Vealer & $0.116 \pm 0.4685$ & 0.804 & $0.137 \pm 0.5692$ & 0.810 & $0.127 \pm 0.6161$ & 0.836 \\
\hline Yearling & $0.075 \pm 0.7946$ & 0.925 & $0.131 \pm 0.9653$ & 0.890 & $0.105 \pm 1.0325$ & 0.919 \\
\hline Fat-3 & $1.746 \pm 0.4420$ & $<0.0001$ & $2.143 \pm 0.5480$ & $<0.0001$ & $2.337 \pm 0.6080$ & $<0.0001$ \\
\hline \multicolumn{7}{|l|}{ SEUROP } \\
\hline $\mathrm{O}$ & $1.832 \pm 0.5840$ & 0.002 & $2.189 \pm 0.7240$ & 0.003 & $2.304 \pm 0.8020$ & 0.005 \\
\hline $\mathrm{R}$ & $3.865 \pm 0.5870$ & $<0.0001$ & $4.731 \pm 0.7270$ & $<0.0001$ & $5.126 \pm 0.8060$ & $<0.0001$ \\
\hline $\mathrm{U}$ & $5.303 \pm 0.8630$ & $<0.0001$ & $6.556 \pm 1.0700$ & $<0.0001$ & $7.180 \pm 1.1860$ & $<0.0001$ \\
\hline \multicolumn{7}{|l|}{ Breed $^{b}$} \\
\hline Crossbred & $28.22 \pm 0.3329^{a}$ & - & $24.05 \pm 0.4043^{a}$ & - & - & - \\
\hline Mirandesa & $27.65 \pm 0.4336^{b}$ & - & $23.52 \pm 0.5286^{b}$ & - & - & - \\
\hline \multicolumn{7}{|l|}{ Gender $^{\mathrm{b}}$} \\
\hline Female & $28.37 \pm 0.4110^{a}$ & - & $24.30 \pm 0.4993^{a}$ & - & $20.39 \pm 0.4887^{a}$ & - \\
\hline Male & $27.51 \pm 0.3018^{b}$ & - & $23.27 \pm 0.3666^{b}$ & - & $19.74 \pm 0.3931^{b}$ & - \\
\hline \multicolumn{7}{|l|}{ Class $^{\mathrm{b}}$} \\
\hline Calf & $26.45+0.3958^{a}$ & - & $21.92 \pm 0.4837^{a}$ & - & $17.72 \pm 0.5978^{a}$ & - \\
\hline Vealer & $27.59 \pm 0.3220^{b}$ & - & $23.33 \pm 0.3935^{b}$ & - & $20.46 \pm 0.4773^{b}$ & - \\
\hline Yearling & $29.01 \pm 0.6880^{c}$ & - & $25.15 \pm 0.8404^{c}$ & - & $23.28 \pm 1.0192^{c}$ & - \\
\hline \multicolumn{7}{|l|}{$\mathrm{Fat}^{\mathrm{b}}$} \\
\hline 2 & $28.15 \pm 0.3260^{a}$ & - & $24.02 \pm 0.4041^{a}$ & - & $20.25 \pm 0.4482^{a}$ & - \\
\hline 3 & $29.89 \pm 0.3481^{b}$ & - & $26.16 \pm 0.4315^{b}$ & - & $22.88 \pm 0.4786^{b}$ & - \\
\hline \multicolumn{7}{|l|}{ SEUROP ${ }^{c}$} \\
\hline $\mathrm{P}$ & $26.27 \pm 0.4400^{a}$ & - & $21.72 \pm 0.5454^{a}$ & - & $18.06 \pm 0.6049^{a}$ & - \\
\hline $\mathrm{O}$ & $28.10 \pm 0.3811^{b}$ & - & $23.91 \pm 0.4724^{b}$ & - & $20.37 \pm 0.5239^{b}$ & - \\
\hline $\mathrm{R}$ & $30.14 \pm 0.3850^{c}$ & - & $26.46 \pm 0.4772^{c}$ & - & $23.19 \pm 0.5239^{c}$ & - \\
\hline $\mathrm{U}$ & $31.57 \pm 0.7470^{d}$ & - & $28.28 \pm 0.9259^{d}$ & - & $25.24 \pm 1.0269^{d}$ & - \\
\hline
\end{tabular}

a Model estimates, standard errors and P-values are shown only for animal/carcass characteristics that were significant in the ANOVA (Pr(F) $<0.10$ ).

b Least-squares means and standard errros of factor levels were computed only when categorical variables (i.e, breed, gender, class, fat) were significant in the ANOVA.

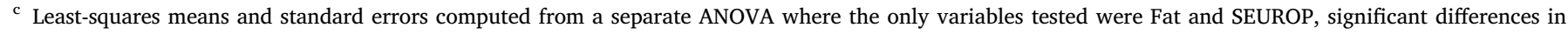
means are denoted by different superscript letters within a factor.

smaller carcasses from calves $\left(23.5^{\circ} \mathrm{C}\right)$. Similarly, greater conformation from "P" to "U" resulted in progressively higher mean rigor temperatures from 20.7 to $27.9^{\circ} \mathrm{C}$, respectively (Table 7 ).

\subsubsection{Carcass classification by quality compliance}

Two orthogonal principal components were found to explain $87.7 \%$ of the total variability in selected animal/carcass characteristics and $\mathrm{pH} /$ temperature decay descriptors (Fig. 3). The first component, which accounted for $48.6 \%$ of the data variability, was negatively correlated with $k_{T}$, while positively and highly correlated with the temperature decay descriptors $T_{1.5}, T_{3.0}, T_{4.5}, T_{6.0}$, and, to a lesser extent, with the animal's age and hot carcass weight. As the series of temperatures at different time points were highly correlated one to another, it was clear that using them all would provide redundant information to the classification algorithms. Thus, only $T_{3.0}$ was selected for inclusion. The second principal component accounted for $39.1 \%$ of the total variability, and was highly correlated with the $p H$ decay descriptors $p H_{1.5}$, $p H_{3.0}, \mathrm{pH}_{4.5}$ and $\mathrm{pH}_{6.0}$.

As occurred in the first component, all of those $\mathrm{pH}$ descriptors contained very similar information as suggested by their high pairwise correlation coefficients (Fig. 3). Thus, from all these $\mathrm{pH}$ at different time points, it was decided to choose the $p H$ after three hours of slaughter $\left(\mathrm{pH}_{3.0}\right)$ for inclusion in the classification analyses, as this was also the only variable highly correlated with both rigor time and rigor temperature.

The variables containing most information that were considered for

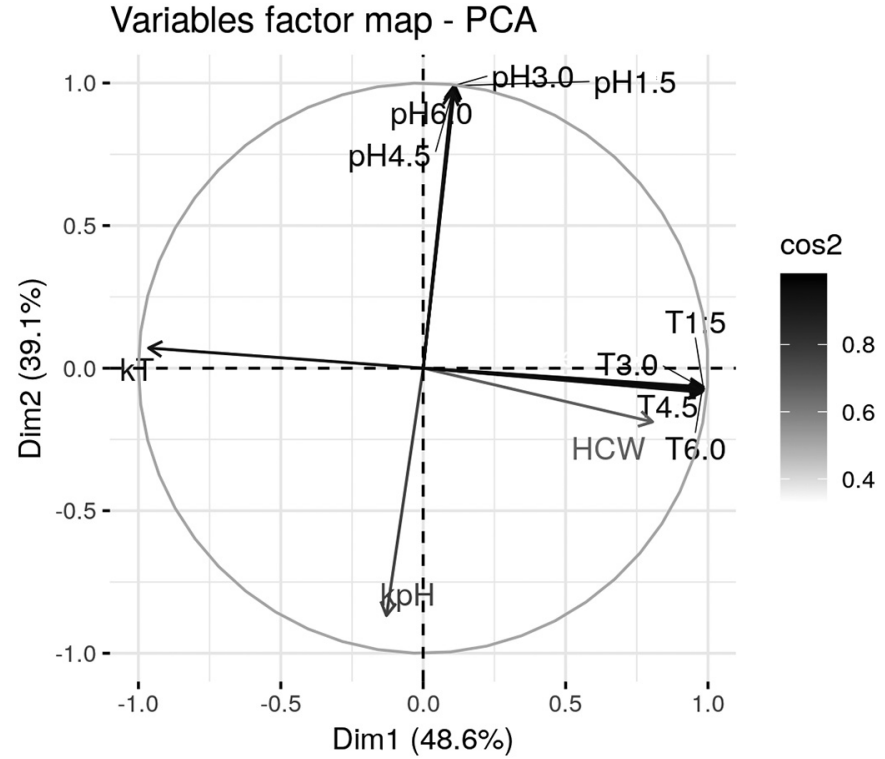

Fig. 3. Loadings map for a two principal component solution showing contribution $\left(R^{2}\right)$ of variables. 


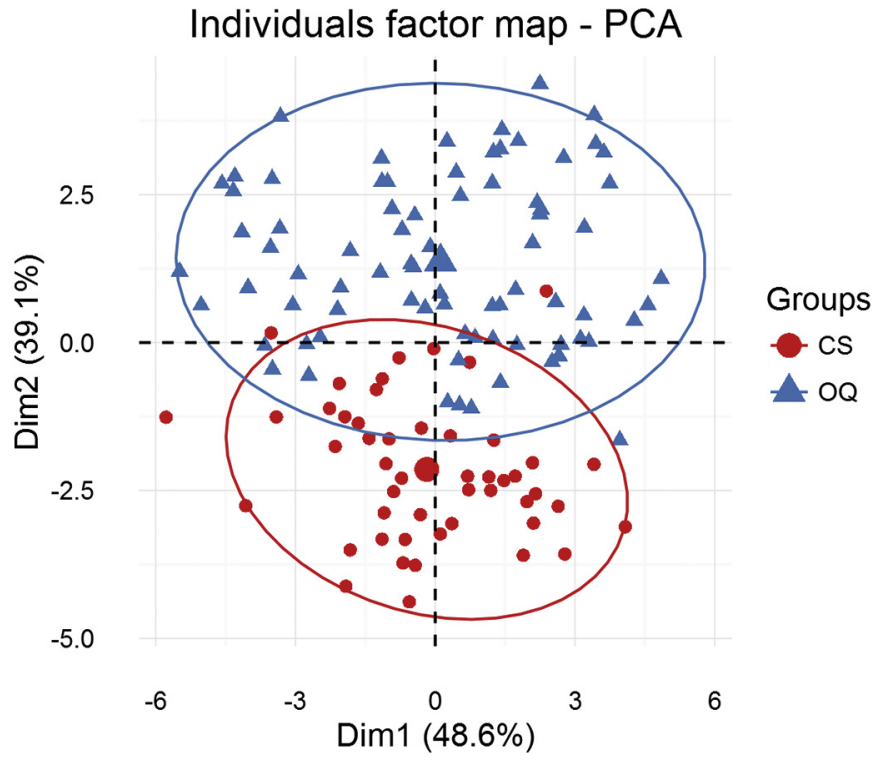

Fig. 4. Scores plot for the two principal component solution showing separability between cold-shortened (CS) and optimal quality (OQ) carcasses.

the prediction of meat quality compliance - according to the ideal window rule, were: $H C W, k_{p H}, k_{T}, p H_{3.0}$ and $T_{3.0}$. With the reduced number of variables, the principal component analysis was re-run, and a score plot of the individual samples was obtained in order to visually assess the separability between cold-shortened and optimal quality carcasses (Fig. 4). The fact that carcasses were distinguished mainly along the y-axis (positive y-axis for optimal quality carcasses and negative $\mathrm{y}$-axis for cold-shortened carcasses) underlines that the $\mathrm{pH}$ decay has a much greater contribution than the temperature decay in determining the carcass quality. Said otherwise, carcasses with slower $p H$ decay (lower $k_{p H}$ ) - and hence with higher $\mathrm{pH}_{3.0}$ - tend to be classified as cold-shortened.

It was calculated that if the $\mathrm{pH}_{3.0}$ is lower than 6.25 , it is very likely to become meat of optimal quality (Fig. 5). By (cross-validation) resampling 100 times the entire data set, it was possible to obtain 100 values of accuracy and kappa statistics for each of the classification algorithms tested. To assess the efficacy of the classification algorithms, box plots of the accuracy and kappa statistics are shown in Fig. 6.

The NSC by far presented the worst classification performance, with not only the lowest mean values of accuracy (0.919) and kappa (0.828) but also the widest range $(0.667-1.000$ and $0.238-1.000$; respectively). A wide confidence interval stems from the fact that, in many iterations, the proportion of misclassification was very high. On the

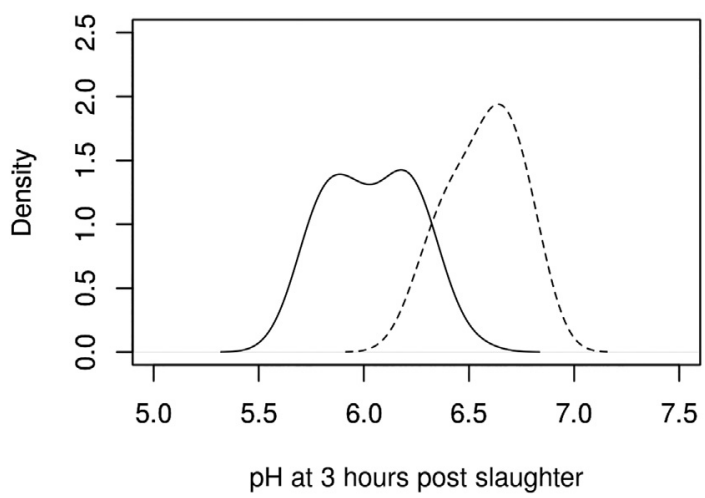

Fig. 5. Density plots of $p H$ values at 3.0 hours post slaughter from cold-shortened (dashed line) and optimal quality (solid line) carcasses. Distributions overlap at a $\mathrm{pH}_{3.0} \sim 6.25$.

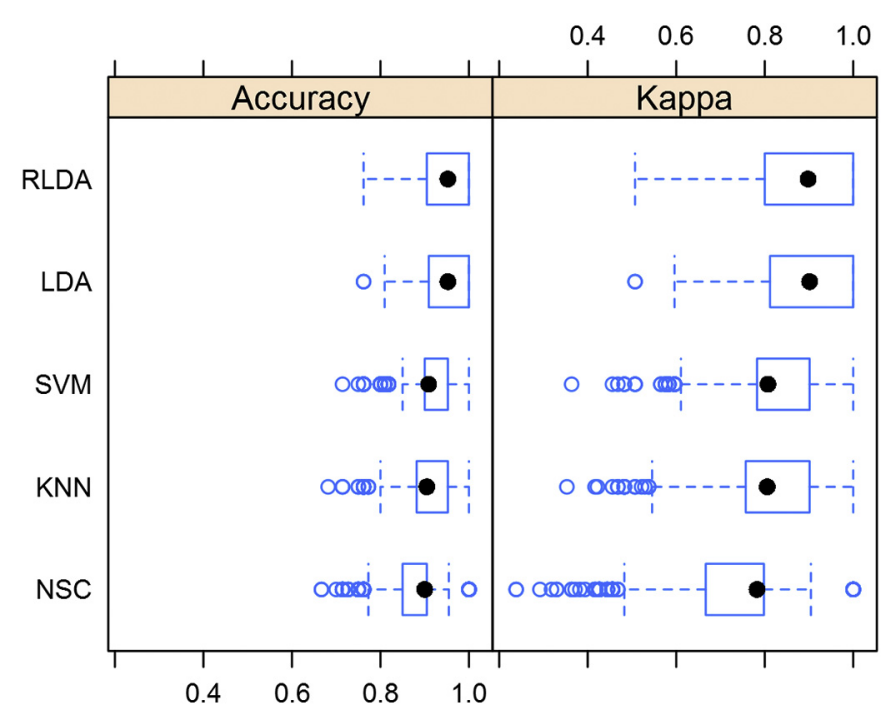

Fig. 6. Box plots of the accuracy and kappa statistics for each of the classification algorithms tested - robust linear discriminant analysis (RLDA), linear discriminant analysis (LDA), k-nearest neighbours (KNN), support vector machines (SVM) and nearest shrunken centroids (NSC) - obtained from resampling the entire data set.

other hand, the SVM and KNN algorithms displayed a similar classification efficacy with comparable mean accuracy $(0.914-0.919)$ and mean kappa ( $0.818-0.828$; Fig. 6). A better classification efficacy was provided by the LDA and the RLDA algorithms in terms of the highest accuracy and kappa statistics, and their narrowest deviations. LDA presented the highest total accuracy (0.951), and when the effect of chance was removed, still had the best performance (kappa $=0.897$ ); although these statistics were not significantly better than those produced by the RLDA method (accuracy $=0.941$; kappa $=0.878$ ).

When the models' performance was compared by randomly splitting the data into train $(70 \%)$ and test data set $(30 \%)$, the classification efficacy of the algorithms ranked similarly (Table 8). NSC was the algorithm with the worst accuracy (0.864) and kappa (0.700) statistics.

Table 8

Confusion matrices, accuracy and kappa indices of the predictions of carcass quality compliance by robust linear discriminant analysis using a separate test data set.

\begin{tabular}{|c|c|c|c|c|c|}
\hline \multirow[t]{2}{*}{ Algorithm $^{\mathrm{a}}$} & \multirow[t]{2}{*}{ Prediction $^{\mathrm{b}}$} & \multicolumn{2}{|c|}{ Reference } & \multirow[t]{2}{*}{ Accuracy $^{\mathrm{c}}(95 \% \mathrm{CI})$} & \multirow[t]{2}{*}{ Kappa $^{\mathrm{d}}$} \\
\hline & & CS & OQ & & \\
\hline \multirow[t]{2}{*}{ RLDA } & CS & 13 & 1 & $0.946(0.818-0.993)$ & $0.885^{\text {**** }}$ \\
\hline & OQ & 1 & 22 & & \\
\hline \multirow[t]{2}{*}{ LDA } & $\mathrm{CS}$ & 13 & 2 & $0.919(0.781-0.983)$ & $0.830^{* * * *}$ \\
\hline & OQ & 1 & 21 & & \\
\hline \multirow[t]{2}{*}{ KNN } & $\mathrm{CS}$ & 12 & 2 & $0.892(0.746-0.970)$ & $0.770^{* * * *}$ \\
\hline & OQ & 2 & 21 & & \\
\hline \multirow[t]{2}{*}{ SVN } & $\mathrm{CS}$ & 12 & 2 & $0.892(0.746-0.970)$ & $0.770^{* * * * *}$ \\
\hline & OQ & 2 & 21 & & \\
\hline \multirow[t]{2}{*}{ NSC } & $\mathrm{CS}$ & 10 & 4 & $0.864(0.712-0.955)$ & $0.700^{* * * * *}$ \\
\hline & OQ & 1 & 22 & & \\
\hline
\end{tabular}

${ }^{a}$ RLDA is robust linear discriminant analysis, LDA is linear discriminant analysis, KNN is k-nearest neighbours, SVM is support vector machines, NSC is nearest shrunken centroids.

b Carcass quality compliance where CS is Cold-shortened and OQ is Optimum quality carcasses.

${ }^{c}$ Accuracy is the sum of true positives and true negatives divided by the total number of items.

${ }^{d}$ Kappa statistic is a metric that compares an observed accuracy with an expected accuracy relative to what would be expected by chance, hence a value of 1 indicates perfect agreement

$$
{ }^{* * * *} p<0.001
$$


Both KNN and SVM misclassified two cold-shortened carcasses as optimal quality carcasses, and two optimal quality carcasses as coldshortened carcasses. The same confusion matrix produced by both classification algorithms led to the same mean accuracy (0.892) and kappa (0.700) statistics. Once again, the LDA and RLDA techniques presented comparable classification efficacy, although, for this particular test data set, RLDA performed slightly better than LDA, as indicated by their total accuracy (0.946 and 0.919 , respectively) and kappa (0.885 and 0.830, respectively) statistics (Table 8). The RLDA classification algorithm mistakenly assigned one optimal quality carcass to the cold-shortening category while another cold-shortened carcass was mistakenly assigned to the optimal quality category.

\section{Conclusions}

The exponential decay model turned out to be an adequate model to describe the carcass' decay in both $p H$ and temperature. Thus, this model allows to calculate a set of early post-mortem $\mathrm{pH}$ and temperature decline descriptors, which together with the animal/carcass characteristics can be used to define carcasses' quality lots pre- and postchilling and/or to monitor the slaughterhouses' chilling protocol.

Linear models adjusted to key descriptors extracted from the fitted $\mathrm{pH} /$ temperature decay curves revealed that more animal/carcass characteristics modulated the carcass temperature decay than the $\mathrm{pH}$ decay. While the temperature-related descriptors were moderated by $H C W$, age class, SEUROP conformation, breed, gender and fat cover; the only three factors affecting the $\mathrm{pH}$-related descriptors were hot carcass weight, age class and SEUROP conformation.

Five variables ( $H C W, k_{p H}, k_{T}, p H_{3.0}$ and $T_{3.0}$ ) can be used to classify beef carcasses according to quality into cold-shortened and optimal quality. This work underscores that it is feasible to classify beef carcasses into cold-shortened and optimal quality from carcasses' $p H$ and temperature monitoring information collected during the first three hours post-slaughter; and $\mathrm{HCW}$, a carcass feature always annotated in a commercial abattoir. Further, research should seek to establish a direct connection between carcasses quality and meat quality, which is the ultimate goal of any carcass classifications system.

\section{Acknowledgments}

The authors are grateful to the support from the'Associação de Criadores de Bovinos de Raça Mirandesa' for kindly providing the meat samples and'Terra Fria Carnes' for putting their slaughterhouse facilities at our disposal during the experimental trials.

\section{References}

Anonymous (2017). Meat Standards Australia beef information kit. Meat \& Livestock Australia Limited.

Bidner, B. S., Ellis, M., Brewer, M. S., Campion, D., Wilson, E. R., \& McKeith, F. K. (2004). Effect of ultimate ph on the quality characteristics of pork. Journal of Muscle Foods, 15(2), 139-154.

Butchers, A. D. M., Ferguson, D. M., Devine, C. E., \& Thompson, J. M. (1998). Interaction between pre-slaughter handling and low voltage electrical stimulation and effect on beef quality. Proceedings of the 44th international congress of meat science and technology (pp. 1050).

Dransfield, E. (1992). Modelling post-mortem tenderisation - III: Role of calpain I in conditioning. Meat Science, 31, 85-94.

Ferguson, D. M. (2004). Objective on-line assessment of marbling: A brief review. Australian Journal of Experimental Agriculture, 44, 681-685.

Ferguson, D. M., Bruce, H. L., Thompson, J. M., Egan, A. F., Perry, D., \& Shorthose, W. R.
(2001). Factors affecting beef palatability - farmgate to chilled carcass. Australian Journal of Experimental Agriculture, 41, 879-891.

from Jed Wing, M. K. C., Weston, S., Williams, A., Keefer, C., Engelhardt, A., Cooper, T., .. Hunt, T. (2018). caret: Classification and regression training. $R$ package version, 6 , $0-79$.

Hamoen, J. R., Vollebregt, H. M., \& van der Sman, R. D. M. (2013). Prediction of the time evolution of ph in meat. Food Chemistry, 141, 2363-2372.

Hopkins, D. L., \& Geesink, G. H. (2009). Applied muscle biology and meat science, chap. Protein degradation post mortem and tenderisation (pp. 149-173). USA: CRC Press, Taylor \& Francis Group.

Hopkins, D. L., Ponnampalam, E. N., van de Ven, R. J., \& Warner, R. D. (2014). The effect of ph decline rate on the meat and eating quality of beef carcasses. Animal Production Science, 54, 407-413.

Hopkins, D. L., Toohey, E. S., Lamb, T. A., Kerr, M. J., van de Ven, R., \& Refshauge, G. (2011). Explaining the variation in the shear force of lamb meat using sarcomere length, the rate of rigor onset and ph. Meat Science, 88(4), 794-796.

Hwang, I. H., Devine, C. E., \& Hopkins, D. L. (2003). The biochemical and physical effects of electrical stimulation on beef and sheep meat tenderness. Meat Science, 65(2), $677-691$.

Hwang, I. H., \& Thompson, J. M. (2001). The interaction between ph and temperature decline early postmortem on the calpain system and objective tenderness in electrically stimulated beef longissimus dorsi muscle. Meat Science, 58(2), 167-174.

Ibarburu, M., Kliebenstein, J. B., \& Hueth, B. M. (2007). ph as a predictor of flavor, juiciness, tenderness and texture in pork from pigs in a niche market system. Animal Industry Report: AS 653, ASL R2181, Iowa State University. URL https : / / i b . dr. iastate.edu/ans air/vol653/iss1/8.

Kahraman, T., Bayraktarōolu, A. G., Issa, G., Ertugrul, T., Bingol, E., \& Ergun, L. (2012). Effects of temperature conditioning and citrus juice marinade on quality and microstructure of aged beef. Journal of Food Agriculture \& Environment, 10, 117-122.

Kassambara, A., \& Mundt, F. (2017). Factoextra: Extract and Visualize the Results of Multivariate Data Analyses. R package version 1.0. 5.

Kim, Y. H. B., Warner, R. D., \& Rosenvold, K. (2014). Influence of high pre-rigor temperature and fast ph fall on muscle proteins and meat quality: A review. Animal Production Science, 54, 375-395.

Kinsella, K. J., Sheridan, J. J., \& Rowe, T. (2006). A study on the use of chilling as a critical control point in a beef HACCP plan. (Research Report No 80. Dublin, Ireland: Ashtown Food Research Centre. ISBN 1-84170-457-X).

Kuhn, M. (2008). Building predictive models in $\mathrm{r}$ using the caret package. Journal of Statistical Software, 28, 1-26.

Lê, S., Josse, J., \& Husson, F. (2008). Factominer: A package for multivariate analysis. Journal of Statistical Software, 25(1), 1-18.

Lomiwes, D., Farouk, M. M., Wiklund, E., \& Young, O. A. (2014). Small heat proteins and their role in meat tenderness: A review. Meat Science, 96, 26-40.

McGeehin, B., Sheridan, J. J., \& Butler, F. (2001). Factors affecting the ph decline in lamb after slaughter. Meat Science, 58(1), 79-84.

Pinheiro, J., Bates, D., DebRoy, S., Sarkar, D., \& Team, R. C. (2018). Nlme: Linear and nonlinear mixed effects models. $R$ package version, 3, 1-131.1.

R Core Team (2017). R: A language and environment for statistical computing. Vienna, Austria: R Foundation for Statistical Computing.

Sánchez, L., Monserrat, L., Brea, T., Dios, A., \& Iglesias, A. (1997). Acabado a diez meses de terneros rubio gallego y rubio gallego holstein en sistemas extensivos: I. Ritmo de crecimiento. ITEA, 18(I), 206-208.

Simmons, N. J., Daly, C. C., Mudford, C. R., Richards, I., Jarvis, G., \& Pleiter, H. (2006). Integrated technologies to enhance meat quality - an australasian perspective. Meat Science, 74(1), 172-179.

Takahashi, G., Wang, S. M., Locher, J. V., \& Marsh, B. B. (1987). Effects of 2-hz and 60-hz stimulation on the microstructure of beef. Meat Science, 19, 65-76.

Thompson, J. (2002). Managing meat tenderness. Meat Science, 62, 295-308.

Thomson, K. L., Gardner, G. E., Simmons, N., \& Thompson, J. M. (2008). Length of exposure to high post-rigor temperatures affects the tenderisation of the beef $\mathrm{m}$. Longissmus dorsi. Australian Journal of Experimental Agriculture, 48(11), 1442-1450.

Tornberg, E. (1996). Biophysical aspects of meat tenderness. Meat Science, 43, S175-S191.

Venables, W. N., \& Ripley, B. D. (2002). Modern applied statistics with S (4th ed.). New York: Springer (ISBN 0-387-95457-0).

Whipple, G., Koohmaraie, M., Dikeman, M. E., \& Crouse, J. D. (1990). Effects of hightemperature conditioning on enzimatic activity and tenderness of bos indicus longissimus muscle. Journal of Animal Science, 68, 3654-3662.

Xavier, C., Gonzales-Barron, U., Muller, A., \& Cadavez, V. (2014). Modelling the temperature and ph decline early post-mortem of beef carcasses. In A. C. Brito, J. M. R. S. Tavares, \& C. B. Oliveira (Eds.). European Simulation and Modelling Conference (pp. 32-35). Porto, Portugal: European Technology Institute, University of Porto (EUROSIS).

Zhou, G., Xu, X., \& Liu, Y. (2010). Preservation technologies for fresh meat - a review. Meat Science, 86(1), 119-128. 